Supplement of Atmos. Chem. Phys., 22, 951-972, 2022

https://doi.org/10.5194/acp-22-951-2022-supplement

(C) Author(s) 2022. CC BY 4.0 License.

(c) (1)

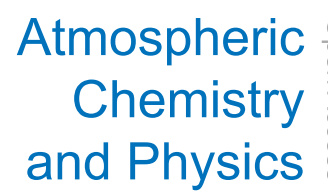

Supplement of

\title{
Data assimilation of $\mathrm{CrIS} \mathrm{NH}_{3}$ satellite observations for improving spatiotemporal $\mathrm{NH}_{3}$ distributions in LOTOS-EUROS
}

Shelley van der Graaf et al.

Correspondence to: Shelley van der Graaf (s.c.vander.graaf@vu.nl)

The copyright of individual parts of the supplement might differ from the article licence. 


\section{Supplementary material}

\section{S.1 Local Ensemble Transform Kalman Filter setting experiments}

Two experiments were performed to study the effect of the LETKF filter settings in more detail. In the first experiment homogeneous $\mathrm{NH}_{3}$ emission fields were used to study the possible emission adjustments that can be achieved by the LETKF.

15 In this experiment, the $\mathrm{NH}_{3}$ base emissions at every grid cell were set to two times the mean $\mathrm{NH}_{3}$ emissions in the Netherlands. The $\mathrm{NH}_{3}$ time factors were kept time-invariant, i.e., set to 1 throughout the year. For different LETKF filter settings, the obtained emission perturbation factors $\beta$ are shown in Fig. S22 and Fig. S23. The experiment shows that increasing temporal length scale $\tau$, i.e., prolonging the time an emission update computed by the LETKF is kept in the model, leads to a larger distribution of computed $\beta$ factors. Imposing more noise on the ensemble members, i.e., a $\sigma$ value to 1 instead of 0.5 , also leads

20 to a larger distribution in $\beta$ factors, as well as an overall increase in $\beta$ factors. The average computed $\beta$ factors illustrate that large-scale spatial patterns in $\mathrm{NH}_{3}$ concentrations, as observed by the CrIS instrument, can be resolved. The distribution of the obtained $\beta$ factors is, except for March, very similar throughout the year. This illustrates that the LETKF is unable to resolve temporal patterns well without sensible initial inputs. In the second experiment the effect of temporal length scale $\tau$ is studied in more detail. In this experiment, our initial model setup was kept, but the temporal length scale is extended to $\tau=10$ days

25 and $\tau=14$ days. The obtained $\beta$ factors are shown in Fig. S24 and Fig. S25. The spatial pattern of the obtained $\beta$ factors remained very similar in all model runs, however, the range in $\beta$ factors increased with increasing $\tau$. Moreover, as patterns of the CrIS- $\mathrm{NH}_{3}$ observations is followed more strongly with increasing $\tau$ values, the obtained spatial variation in $\beta$ factors became more distinct. 

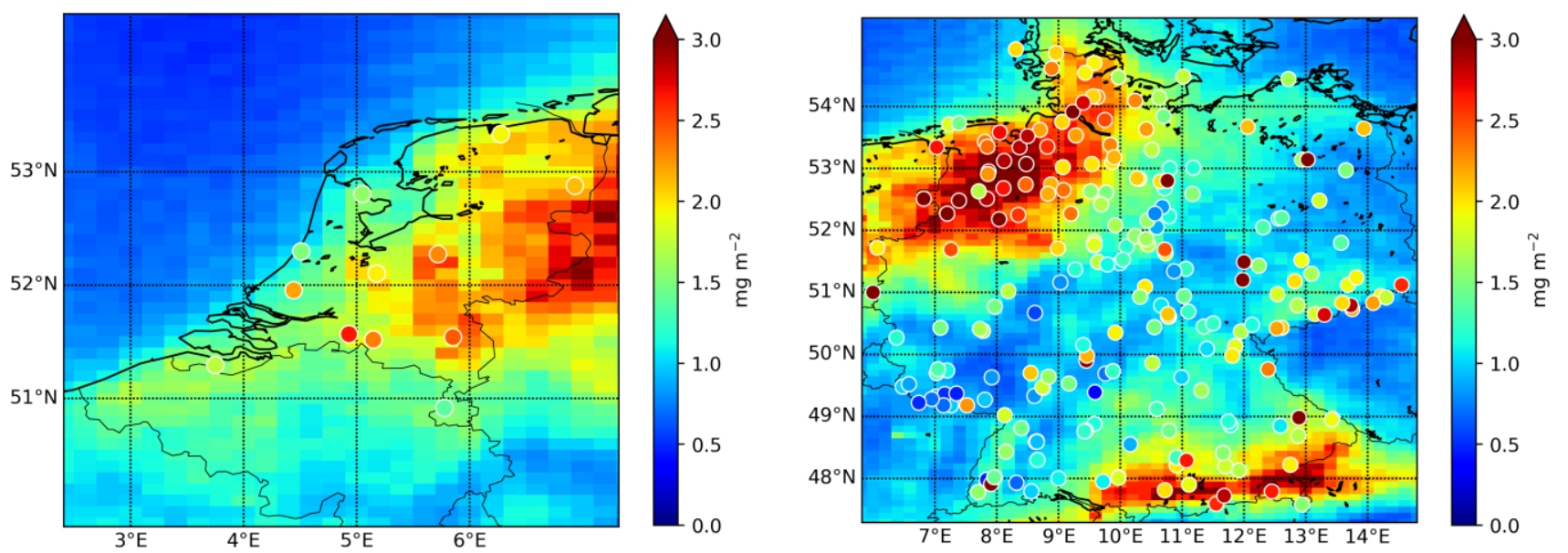

Figure S1: Locations of the wet-only samplers used in this study, plotted on top of the modelled mean $\mathrm{NH}_{4}$ wet deposition in 2014 to 2018.

Scaling factor applied for high emission pixels $\left(>0.0025 \mathrm{~kg} \mathrm{NH}_{3} \mathrm{~m}^{-2} \mathrm{yr}^{-1}\right)$ in 2014
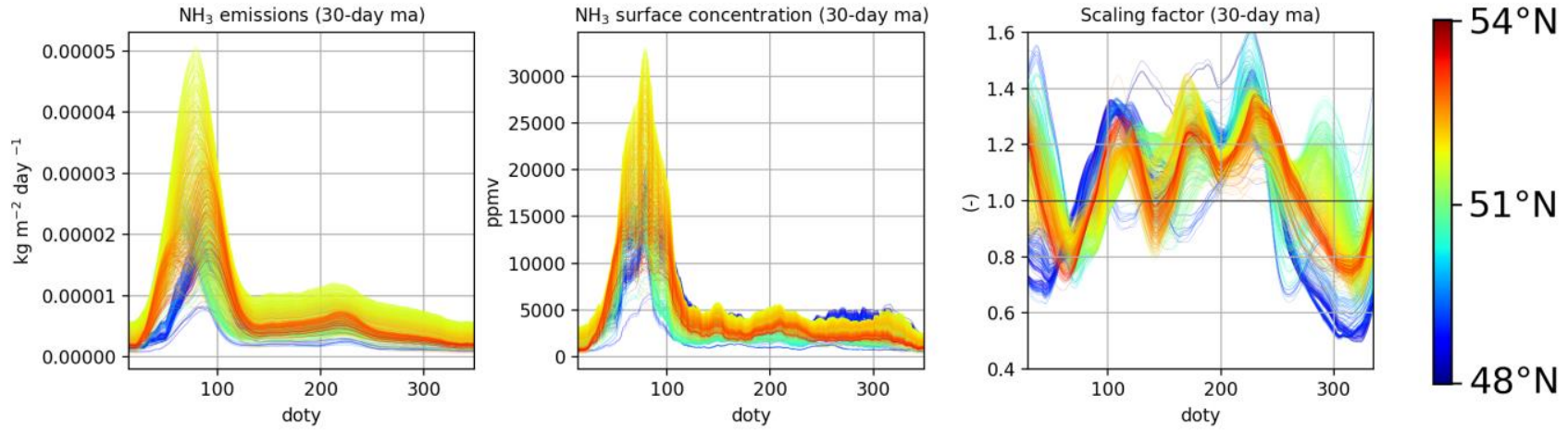

Figure S2: Example of the calculated scaling factors applied to correct for $\mathrm{NH}_{3}$ surface concentration to $\mathrm{NH}_{3}$ emission ratios in 2014. 
Mean CrIS NH $\mathrm{N}_{3}$ total column

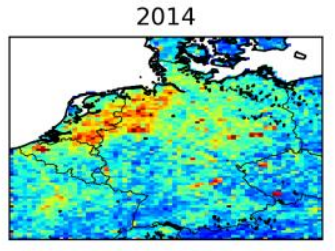

$\begin{array}{lllll}0.5 & 1.0 & 1.5 & 2.0 & 2.5\end{array}$ (molecules $\mathrm{cm}^{-2}$ ) $1 \mathrm{el6}$

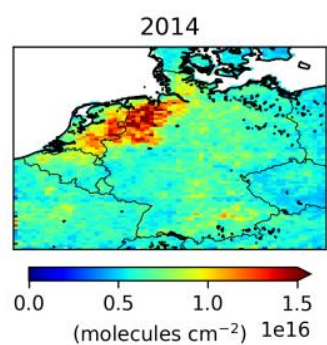

2015

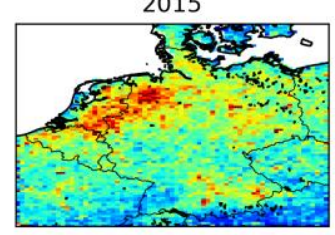

$\begin{array}{llllr}0.5 & 1.0 & 1.5 & 2.0 & 2.5\end{array}$

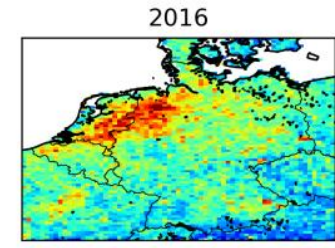

$\begin{array}{lllll}0.5 & 1.0 & 1.5 & 2.0 & 2.5\end{array}$ (molecules $\mathrm{cm}^{-2}$ ) $1 \mathrm{e} 16$

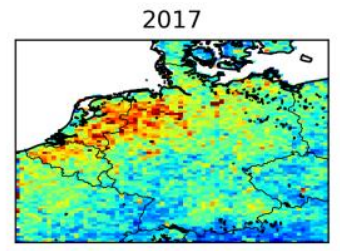

$\begin{array}{lllll}0.5 & 1.0 & 1.5 & 2.0 & 2.5\end{array}$ (molecules $\mathrm{cm}^{-2}$ ) $1 \mathrm{e} 16$

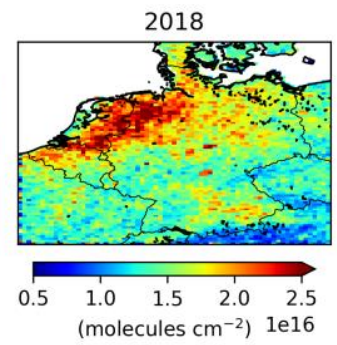

Mean simulated $\mathrm{NH}_{3}$ total column $\left(\mathrm{x}_{\mathrm{b}}\right)$
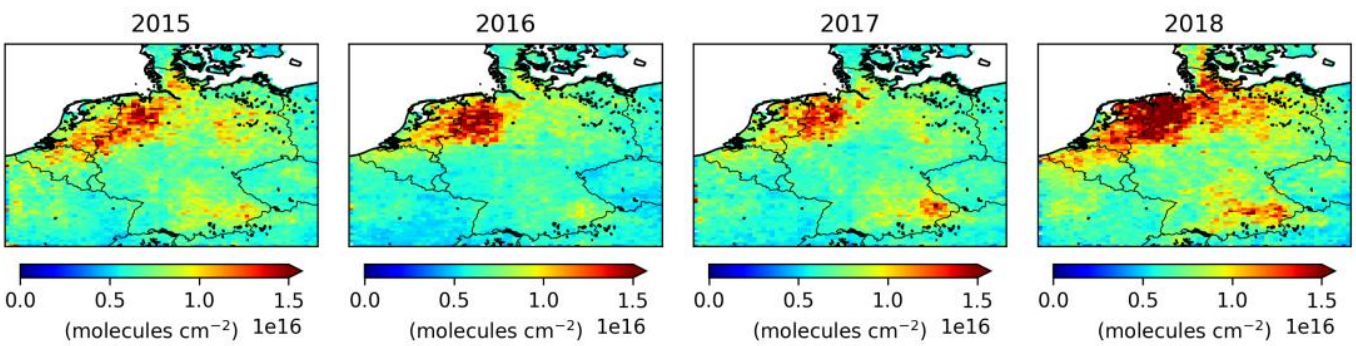

40 Figure S3: Retrieved (top) and simulated (bottom) $\mathbf{N H}_{3}$ total column per year. 

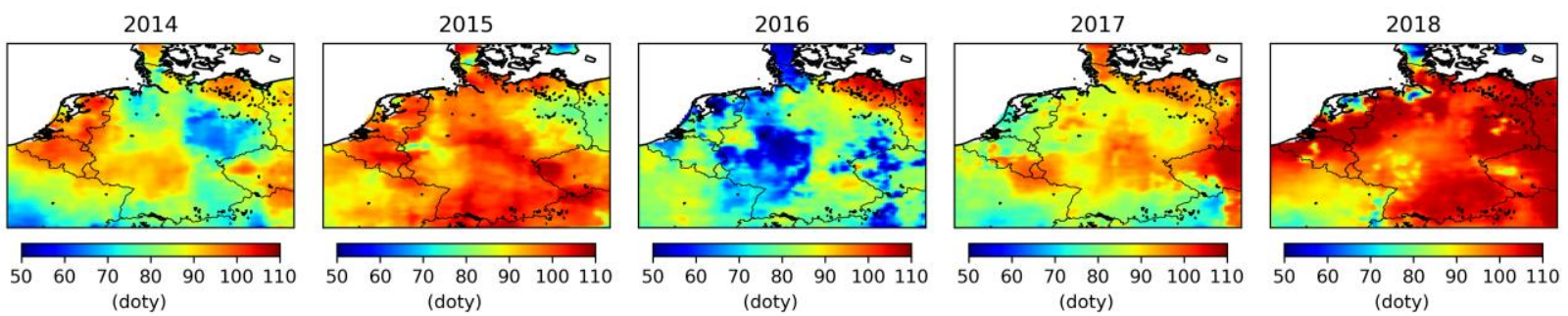

Spring peak standard deviation $\left(\sigma_{1}\right)$
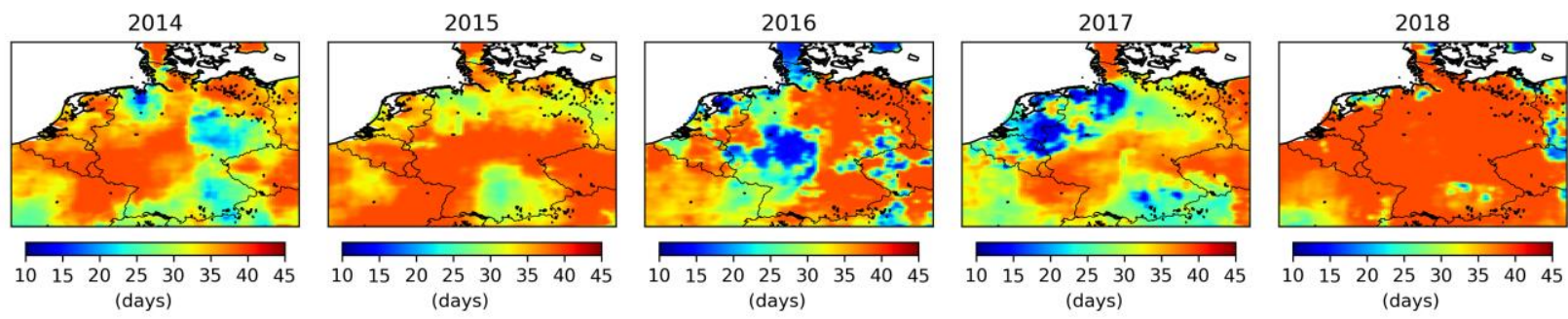

Spring peak amplitude $\left(A_{1}\right)$
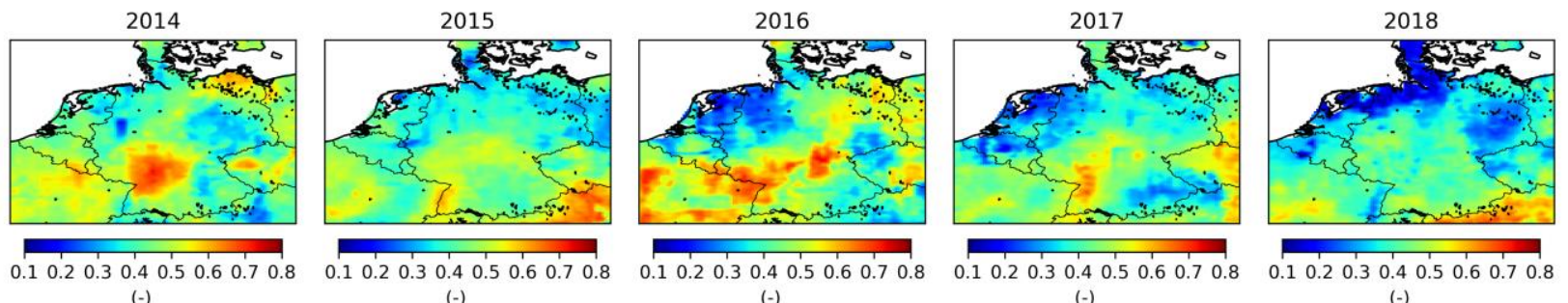

45 Figure $S_{4}$ : The fitted spring peak parameters $\left(\mu_{1}, \sigma_{1}\right.$ and $\left.A_{1}\right)$ per year. 
Mean $\mathrm{NH}_{3}$ total column (2014-2018)
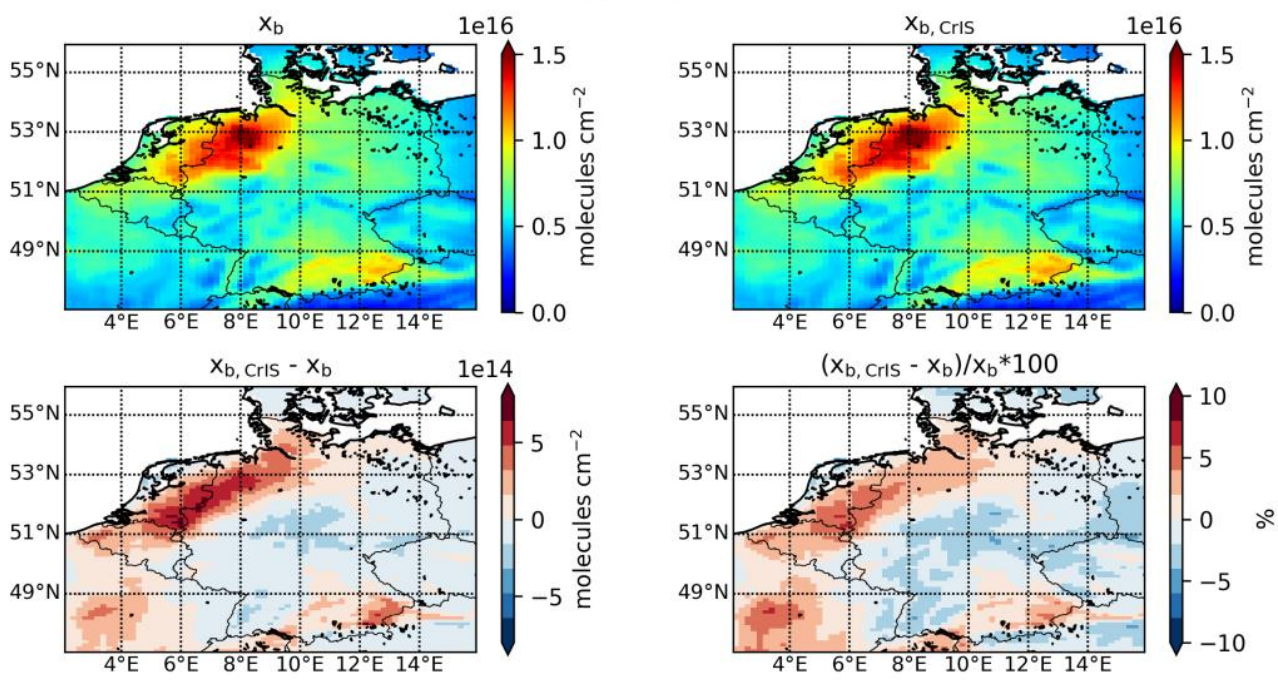

Figure S5: The mean $\mathrm{NH}_{3}$ total column over 2014 to 2018 from the (top left) default background run (xb) and the (top right) background run with CrIS-based $\mathrm{NH}_{3}$ time factors $\left(\mathrm{x}_{\mathrm{b}, \mathrm{CrIS}}\right)$ and their (bottom left) absolute and (bottom right) relative difference.
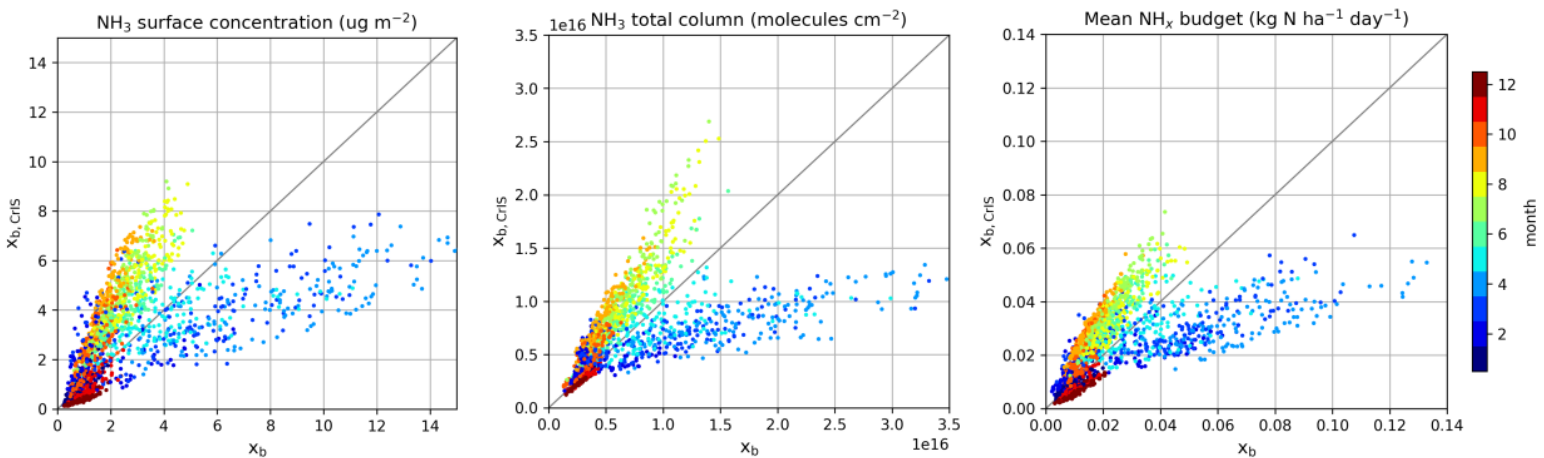

Figure S6: Scatter plots of the daily grid-averaged $\mathrm{NH}_{3}$ Surface concentration (left), $\mathrm{NH}_{3}$ total column (center) and $\mathrm{NH}_{\mathrm{x}}$ deposition

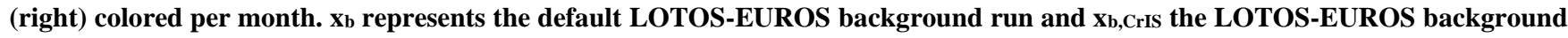
run with CrIS-based $\mathrm{NH}_{3}$ time factors. 

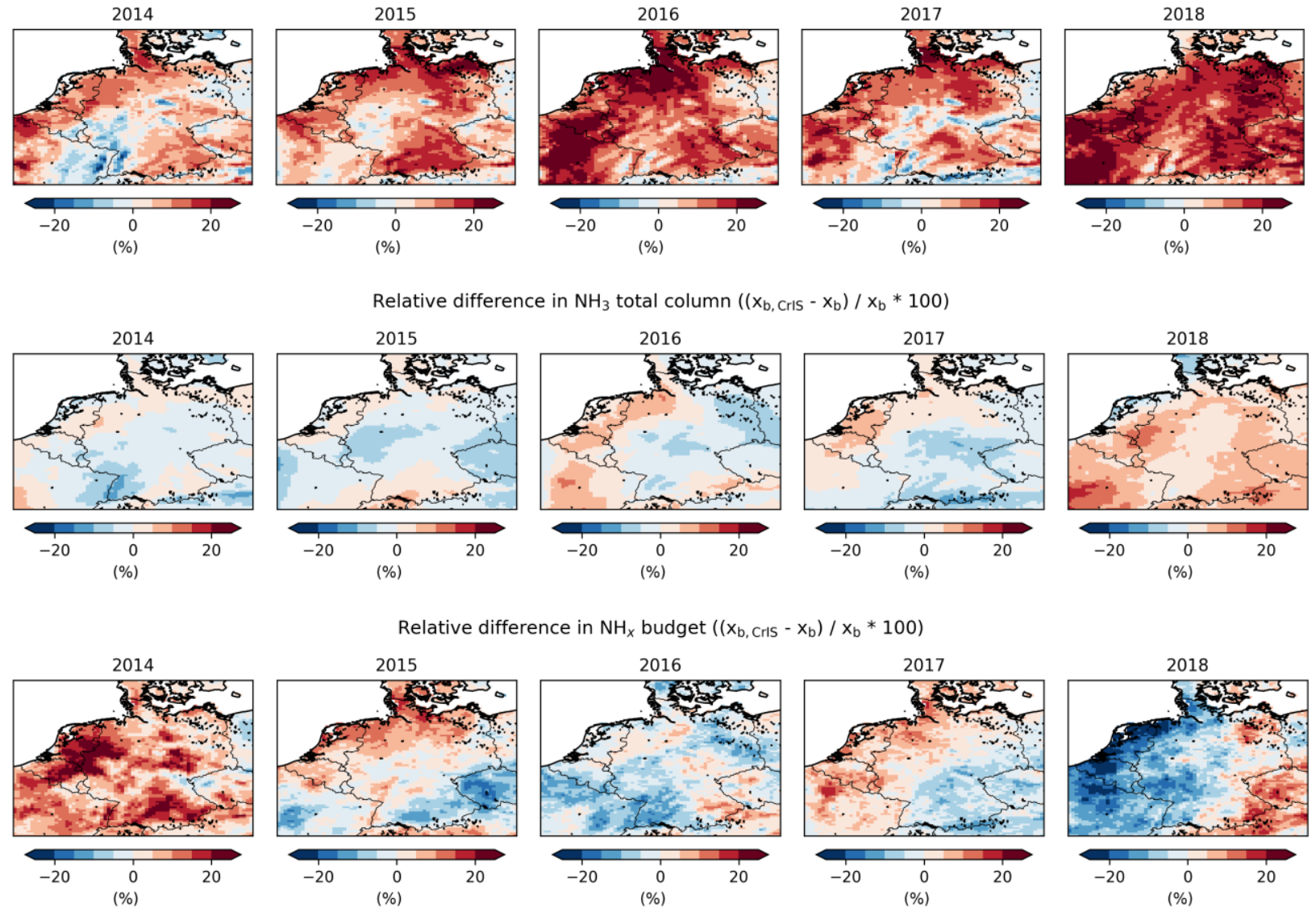

Figure S7: Relative difference in mean $\mathrm{NH}_{3}$ surface concentrations (top), total column concentrations (center) and total $\mathrm{NH}_{\mathrm{x}}$

60 deposition (bottom) per year following the inclusion of the CrIS-based $\mathrm{NH}_{3}$ time factors in LOTOS-EUROS. $\mathrm{x}_{\mathrm{b}}$ represents the default LOTOS-EUROS background run and $\mathrm{xb}$,CrIS the LOTOS-EUROS background run with CrIS-based $\mathrm{NH}_{3}$ time factors. 

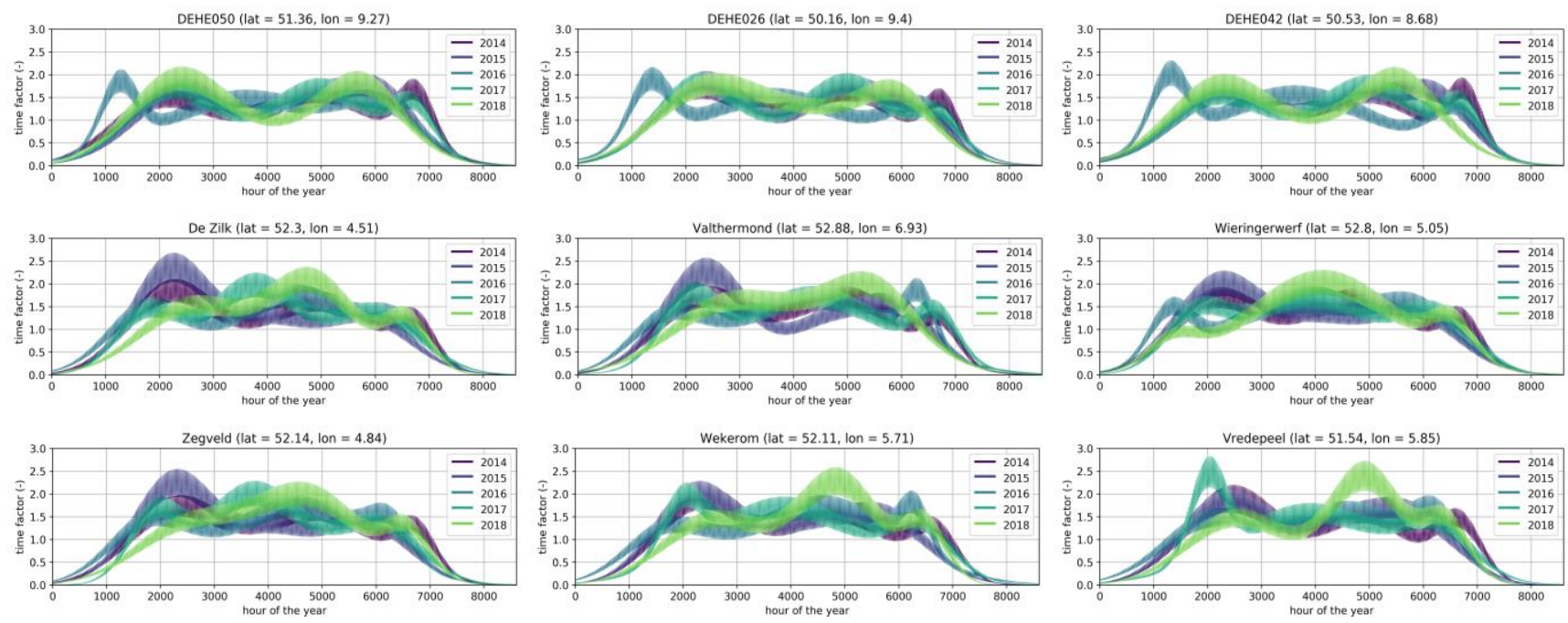

Figure S8: The CrIS-based $\mathrm{NH}_{3}$ time factors at the hourly observation stations.

65 

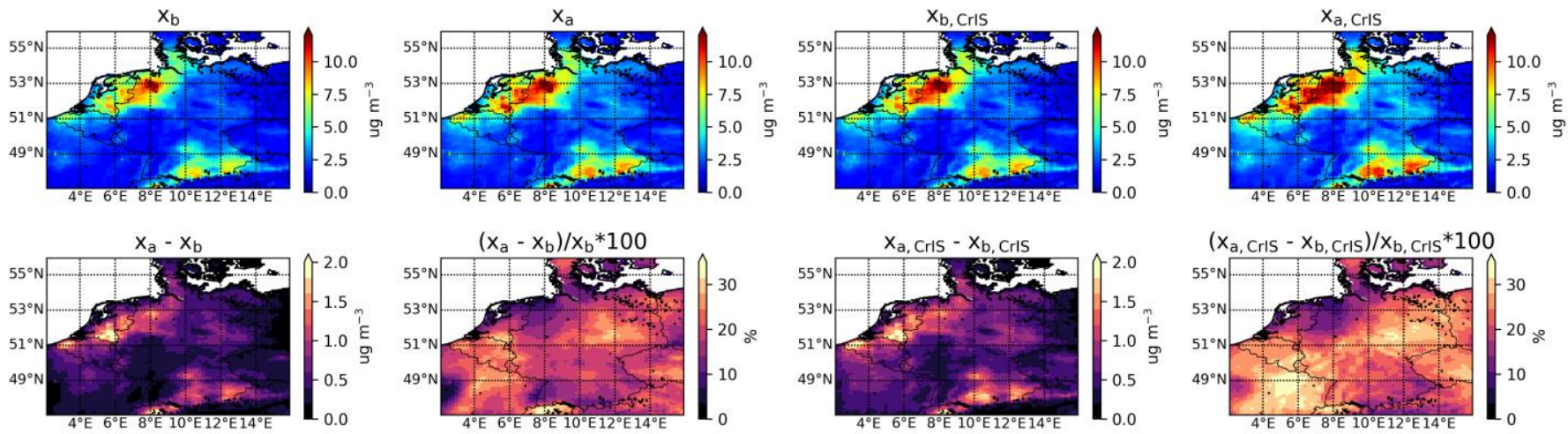

Figure S9: Mean $\mathrm{NH}_{3}$ surface concentration in 2014-2018 in the background runs $\mathrm{x}_{\mathrm{b}}$ and $\mathrm{x}_{\mathrm{b}}$, CrIS and in analysis runs $\mathrm{x}_{\mathrm{a}}$ and $\mathrm{x}_{\mathrm{a}, \mathrm{CrIS}}$ (top panels), as well as their absolute and relative difference (bottom panels).
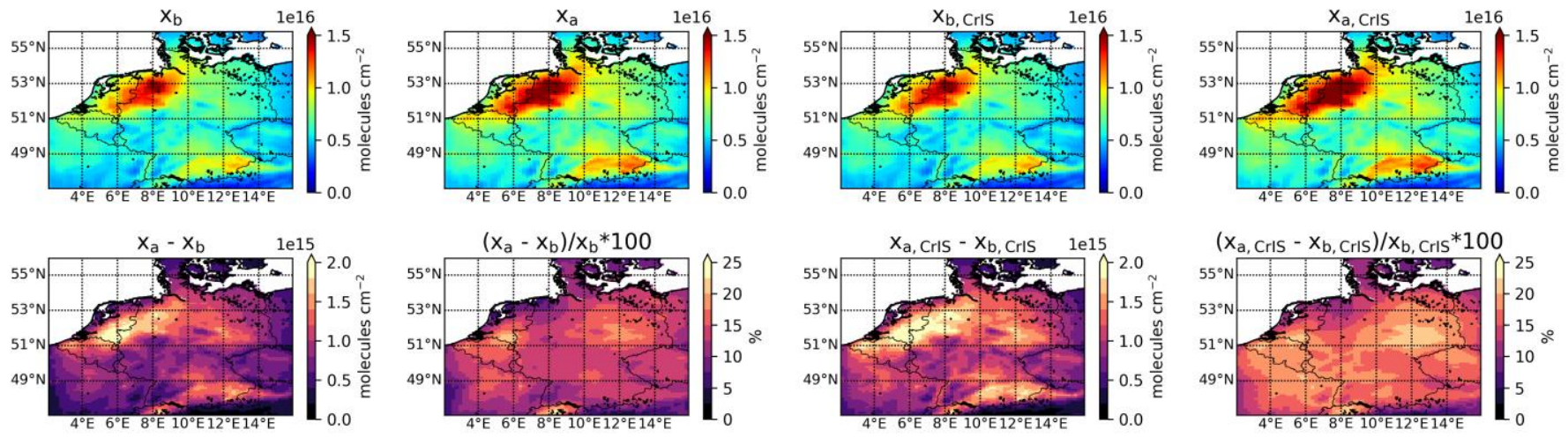

Figure S10: Mean $\mathrm{NH}_{3}$ total column concentration in 2014-2018 in the background runs $\mathrm{x}_{\mathrm{b}}$ and $\mathrm{x}_{\mathrm{b}}$, Cris and in analysis runs $\mathrm{x}_{\mathrm{a}}$ and $\mathrm{x}_{\mathrm{a}, \mathrm{CrIS}}$ (top panels), as well as their absolute and relative difference (bottom panels). 

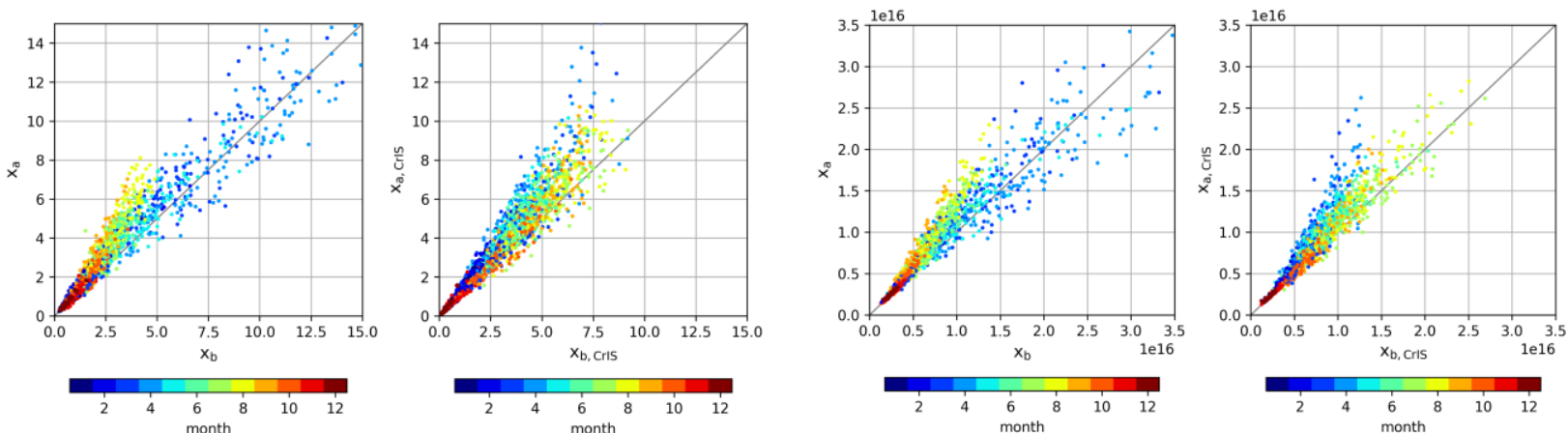

Figure S11: Scatter plots of the daily grid-averaged $\mathrm{NH}_{3}$ surface concentration (left) and $\mathrm{NH}_{3}$ total column concentration (right) in 2014-2018 from the background runs $x_{b}$ and $x_{b}$, CrIS versus analysis runs $x_{a}$ and $x_{a}$, Cris in LOTOS-EUROS, colored per month.
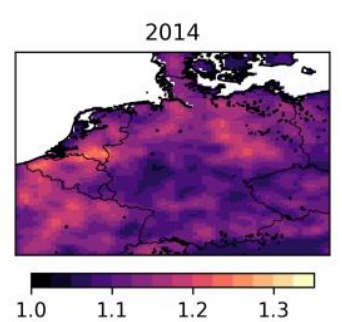

$(-)$
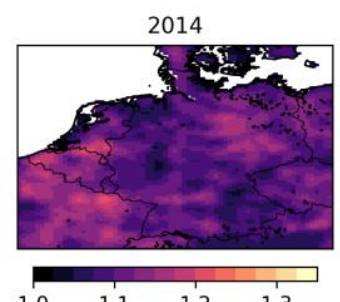

90

$(-)$
Mean dc factor $\left(x_{a}\right)$
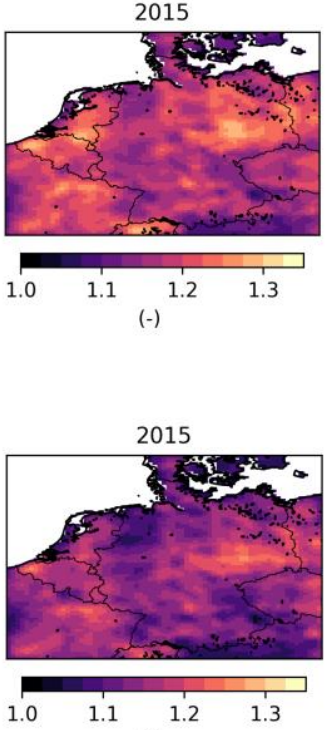

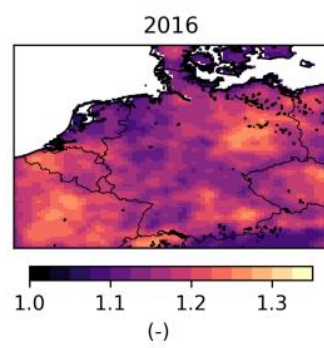

Mean dc factor ( $x_{a}$, cris)

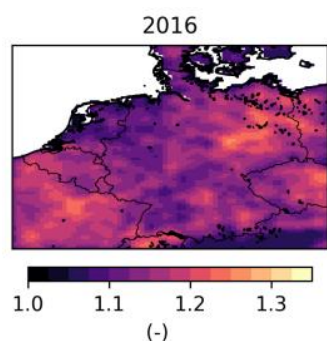

2017

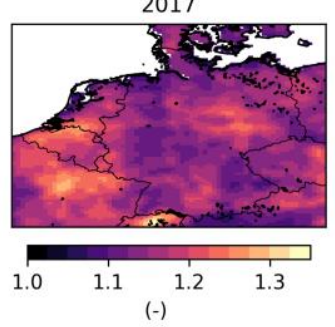

2017

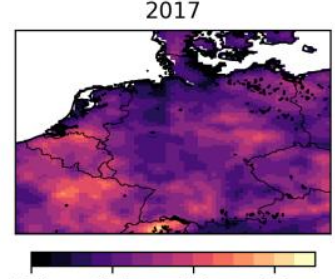

10

$(-)$

$(-)$
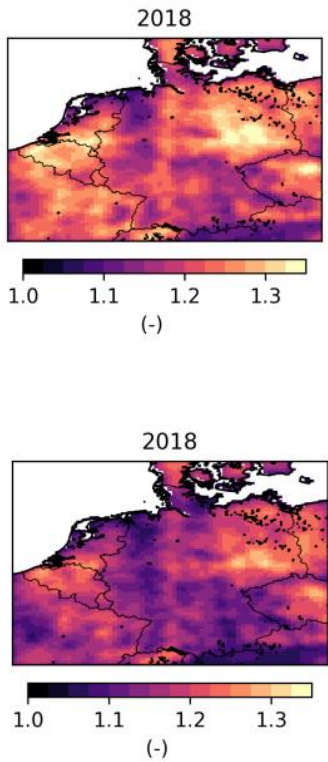

Figure S12: Mean emission perturbation factors ( $\beta$ ) per year for (top) LOTOS-EUROS runs with default $\mathrm{NH}_{3}$ emission time factors and (bottom) LOTOS-EUROS runs with CrIS-based $\mathrm{NH}_{3}$ time factors. 

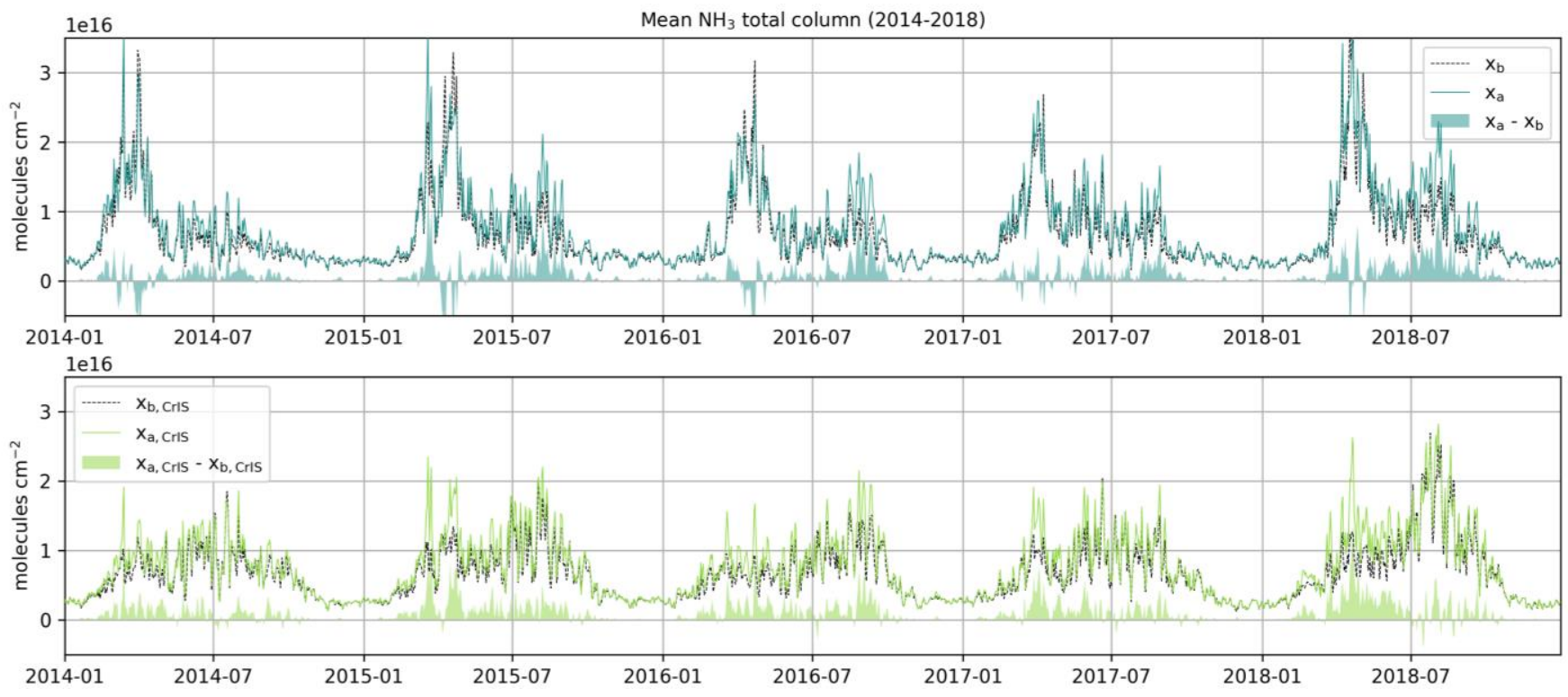

95 Figure S13: Timeseries of the daily grid-averaged $\mathrm{NH}_{3}$ total column concentrations in the background and analysis runs, and their absolute difference. The top figure (blue) represents the default background ( $\left.x_{b}\right)$ and analysis run $\left(x_{a}\right)$. The bottom figure (green) the background $\left(\mathrm{x}_{\mathrm{b}, \mathrm{CrIS}}\right)$ and analysis run $\left(\mathrm{x}_{\mathrm{a}, \mathrm{CrIS}}\right)$ with the CrIS-based $\mathrm{NH}_{3}$ time factors.

Daily $\mathrm{NH}_{x}$ dry deposition $\left(\mathrm{kg} \mathrm{N}_{\mathrm{Na}}{ }^{-1}\right.$ day $\left.^{-1}\right)$

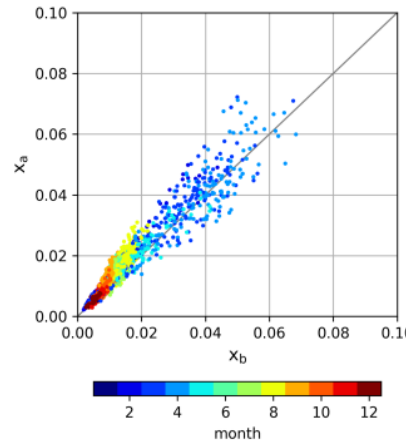

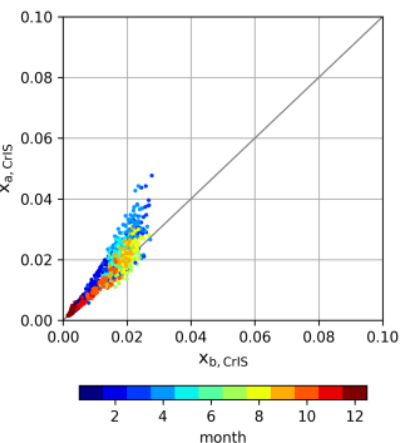

Daily $\mathrm{NH}_{x}$ wet deposition $\left(\mathrm{kg} \mathrm{N}^{-1} \mathrm{day}^{-1}\right)$
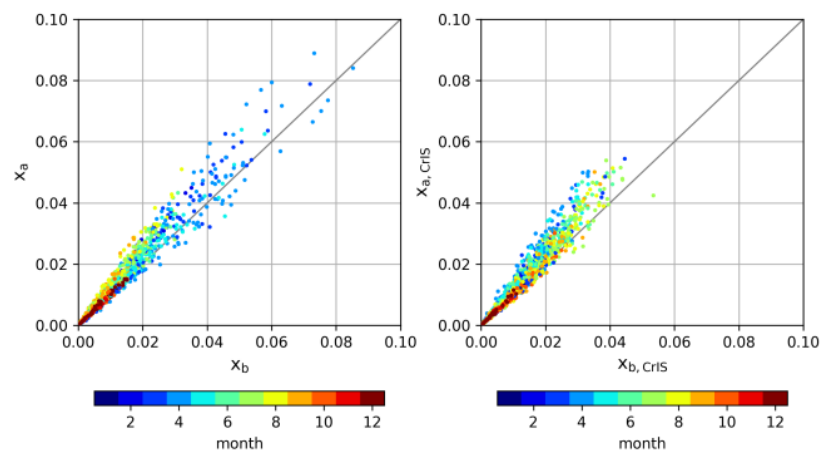

100 Figure S14: Scatter plots of the daily grid-averaged amounts of dry (left) and wet (right) $\mathbf{N H}_{\mathbf{x}}$ deposition in $2014-2018$ from the background ( $x_{b}$ and $\left.x_{b}, C r I S\right)$ versus the analysis $\left(x_{a}\right.$ and $\left.x_{a, C r I S}\right)$ model runs in LOTOS-EUROS, colored per month. 

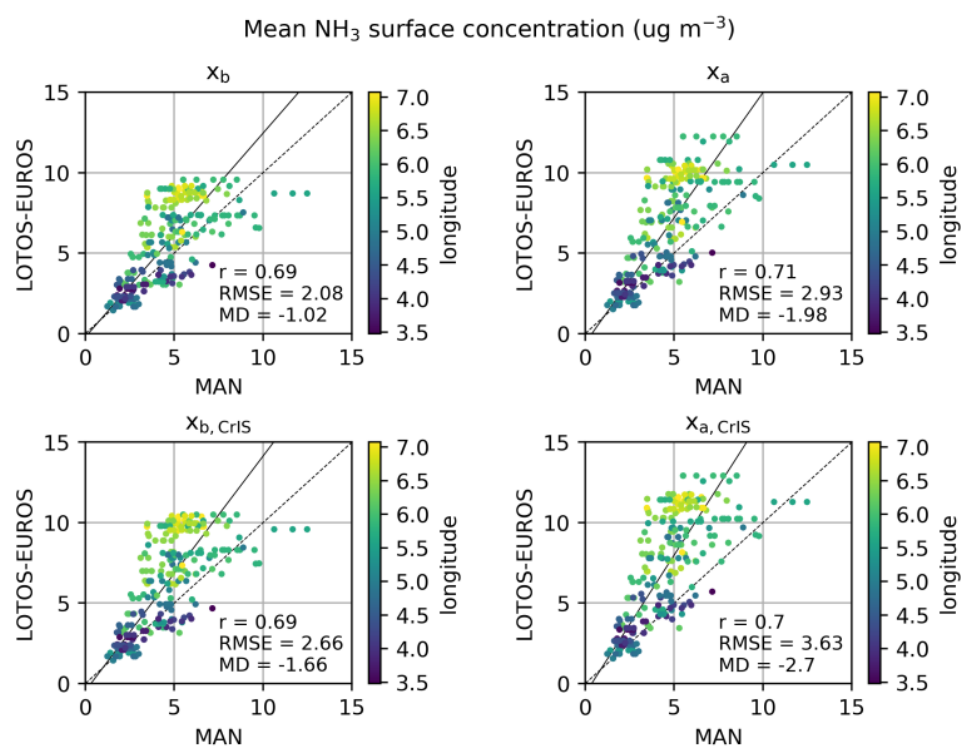

Figure S15: Mean $\mathrm{NH}_{3}$ surface concentrations (2014-2017) as observed by the Dutch MAN stations and the matching modelled values. The upper figures represent the matching mean $\mathrm{NH}_{3}$ surface concentrations from the default version of LOTOS-EUROS: $\mathrm{x}_{b}$ the background run and $x_{a}$ the analysis run. The lower figures represent the matching values from the LOTOS-EUROS run with the CrIS-based $\mathrm{NH}_{3}$ time factors: $\mathrm{x}_{\mathrm{b}}$,CrIS the background run and $\mathrm{x}_{\mathrm{a}, \mathrm{CrIS}}$ the analysis run.
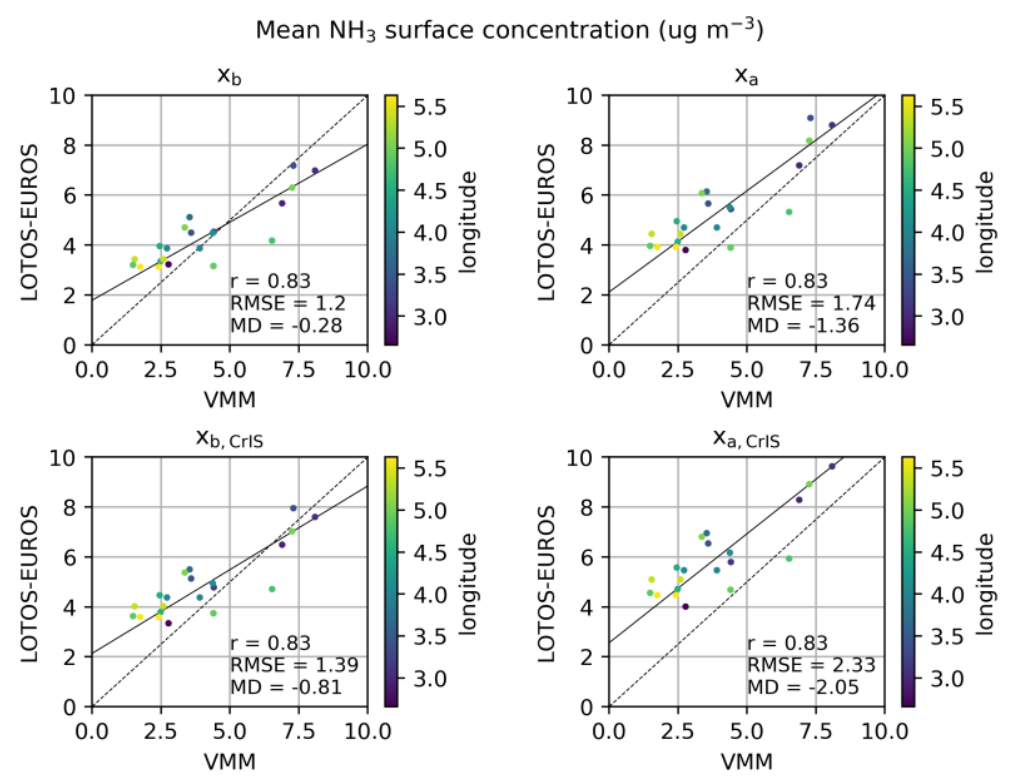

Figure S16: Mean $\mathrm{NH}_{3}$ surface concentrations (2014-2018) as observed by the Belgium VMM stations and the matching modelled

110 values. The upper figures represent the matching mean $\mathrm{NH}_{3}$ surface concentrations from the default version of LOTOS-EUROS: $\mathrm{x}_{\mathrm{b}}$ the background run and $x_{a}$ the analysis run. The lower figures represent the matching values from the LOTOS-EUROS run with the CrIS-based $\mathrm{NH}_{3}$ time factors: $\mathrm{x}_{b}$,CrIS the background run and $\mathrm{x}_{a}, \mathrm{CrIS}$ the analysis run. 

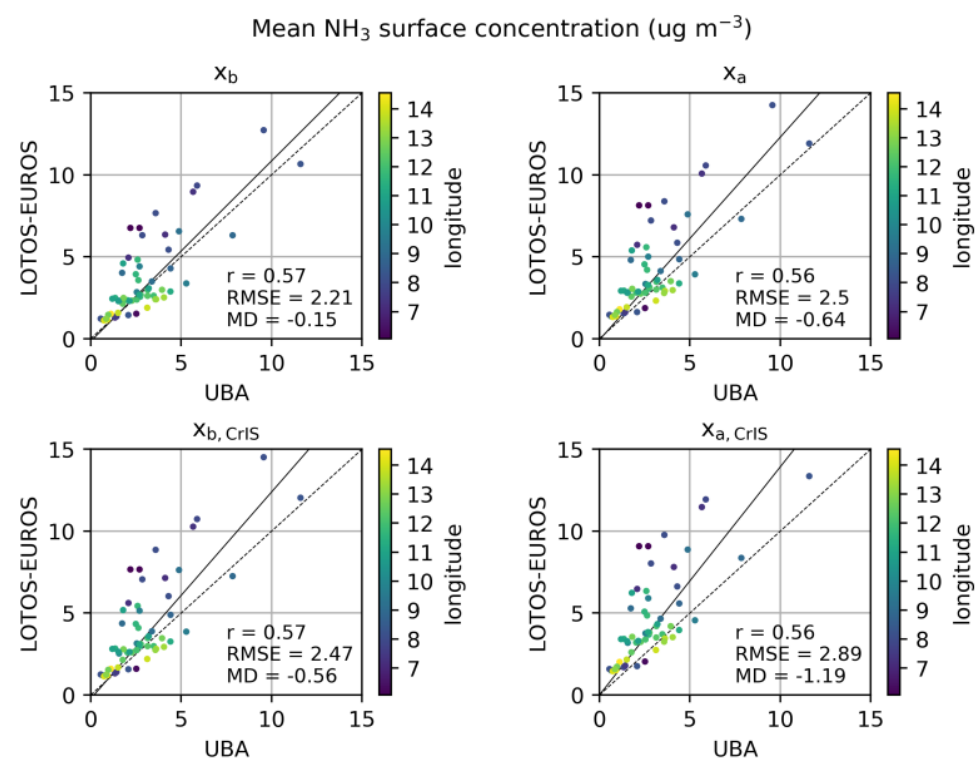

Figure S17: Mean $\mathrm{NH}_{3}$ surface concentrations (2014-2018) as observed by the German passive sampler stations and the matching modelled values. The upper figures represent the matching mean $\mathrm{NH}_{3}$ surface concentrations from the default version of LOTOSEUROS: $x_{b}$ the background run and $x_{a}$ the analysis run. The lower figures represent the matching values from the LOTOS-EUROS run with the CrIS-based $\mathrm{NH}_{3}$ time factors: $\mathrm{x}_{b}$,CrIS the background run and $\mathrm{x}_{\mathrm{a}, \mathrm{CrIS}}$ the analysis run.

Hourly observation networks (LML and UBA)
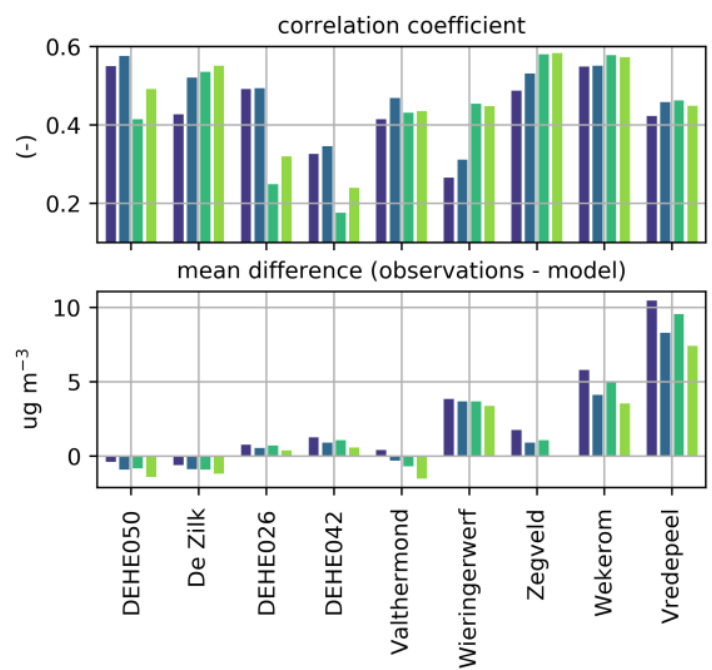

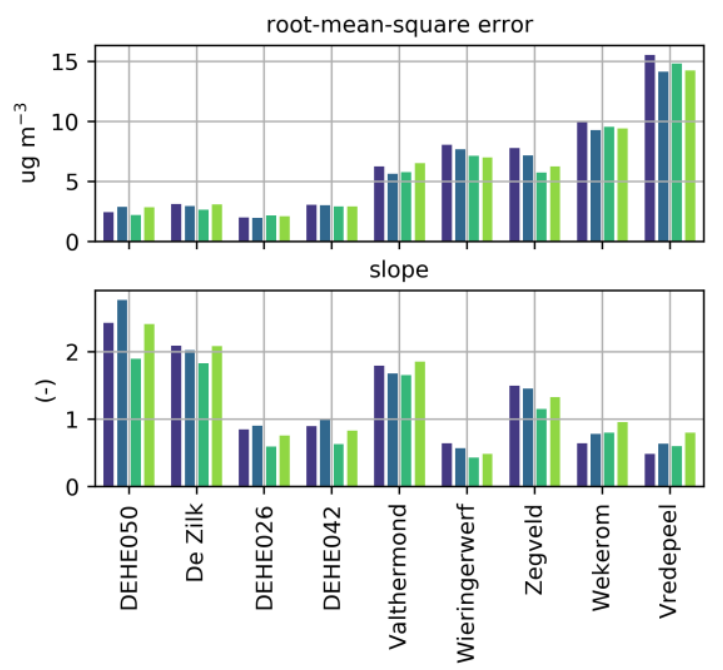

120 Figure S18: Correlation coefficient r, root-mean-square error, differences in means, slope and intercept between the observed and modelled $\mathrm{NH}_{3}$ surface concentrations. The stations are sorted by increasing mean $\mathrm{NH}_{3}$ surface concentration. The colors of the bars represent the different background ( $x_{b}$ and $\left.x_{b}, C r I S\right)$ and analysis ( $x_{a}$ and $\left.x_{a}, C r I s\right)$ runs. 

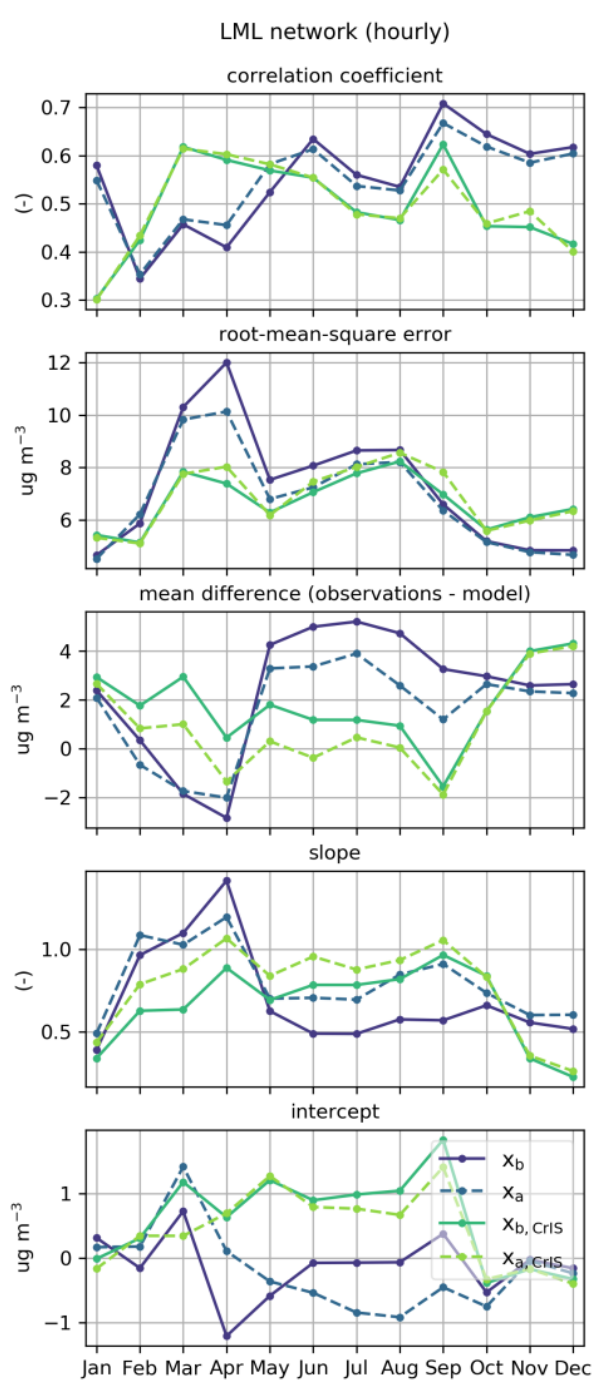
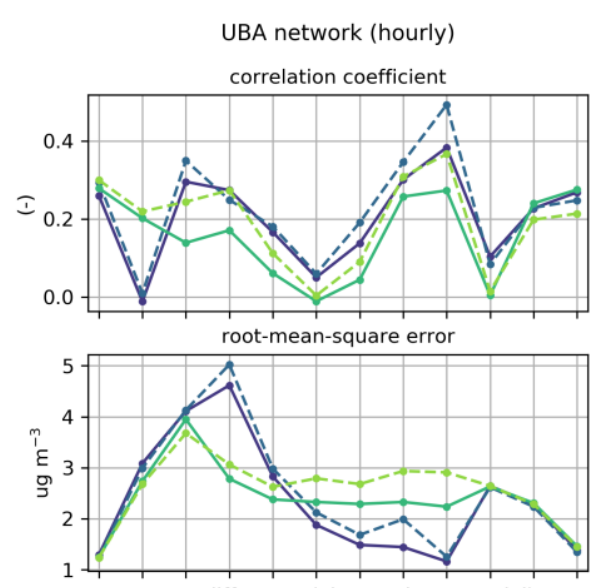

mean difference (observations - model)
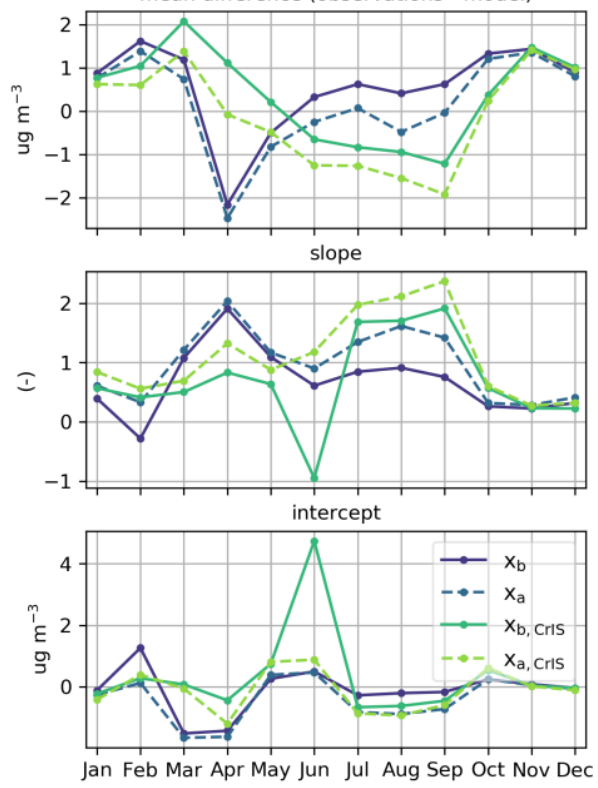

Figure S19: Monthly comparison of the observed and modelled $\mathrm{NH}_{3}$ surface concentrations per hourly observation network. From

125 top to bottom, the Pearson's correlation coefficient $\mathbf{r}$, the root-mean-square error, the differences in means, the slope and the intercept are plotted. The purple lines represent the default version of LOTOS-EUROS ( $x_{b}$ being the background run, $x_{a}$ the analysis run) and the green lines the version of LOTOS-EUROS with the CrIS-based $\mathrm{NH}_{3}$ time factors ( $\mathrm{x}_{\mathrm{b}, \mathrm{CrIS}}$ the background run, $\mathrm{x}_{\mathrm{a}, \mathrm{CrIS}}$ the analysis run). 

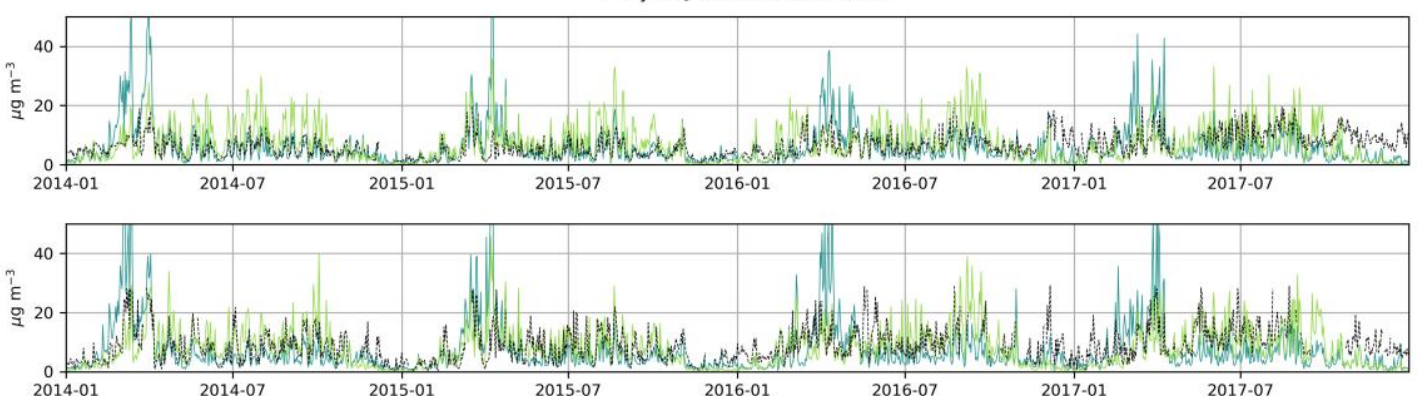

Zegveld

$x_{b}(r=0.49$, RMSE $=7.79)$

$x_{b, \text { CrIS }}(r=0.58$, RMSE $=5.73)$

130 Figure S20: Example of the observed and modelled daily NH3 surface concentrations at LML stations Valthermond and Zegveld. $\mathbf{x b}_{\mathbf{b}}$ represents the default LOTOS-EUROS background run and $\mathrm{x}_{\mathrm{b}, \mathrm{CrIS}}$ the LOTOS-EUROS background run with CrIS-based NH $\mathrm{N}_{3}$ time factors.

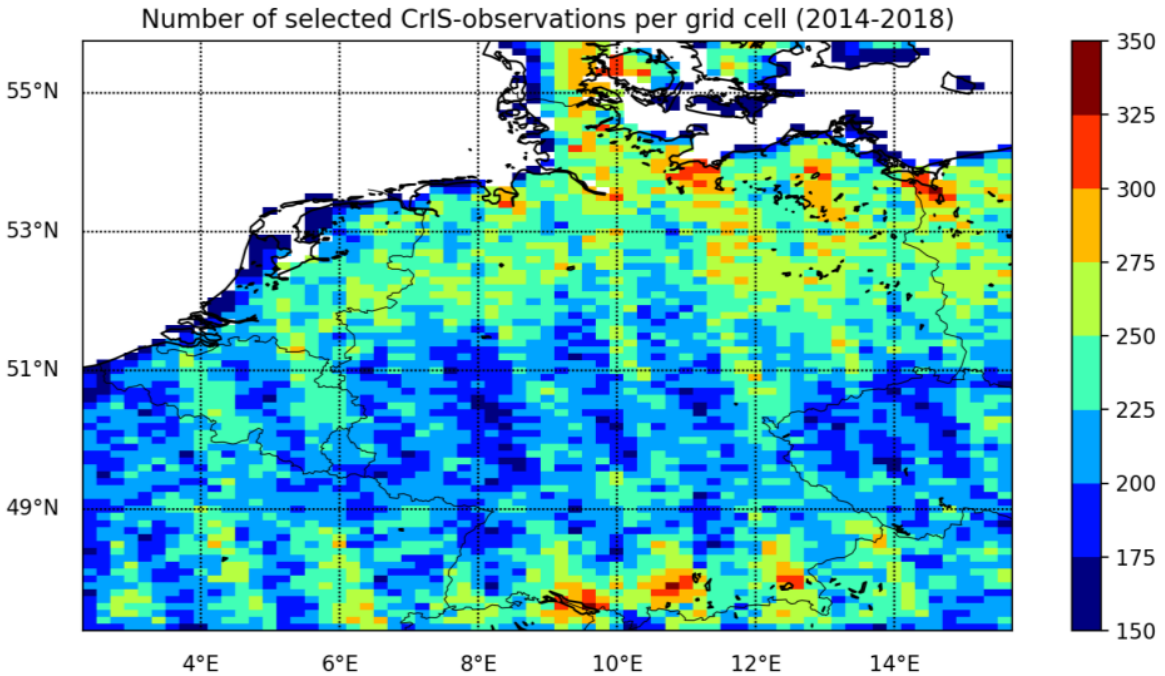

Figure S21: Number of selected CrIS-NH3 observations per grid cell. 

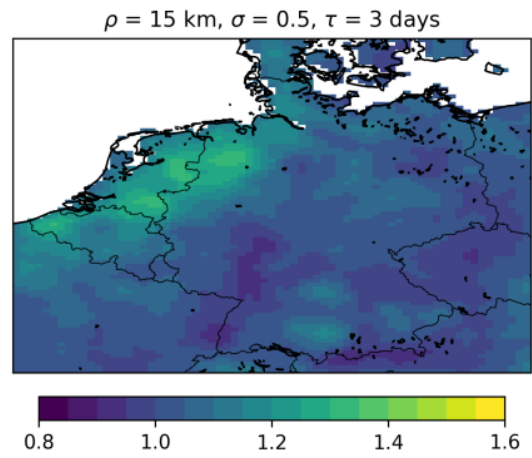

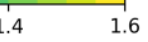

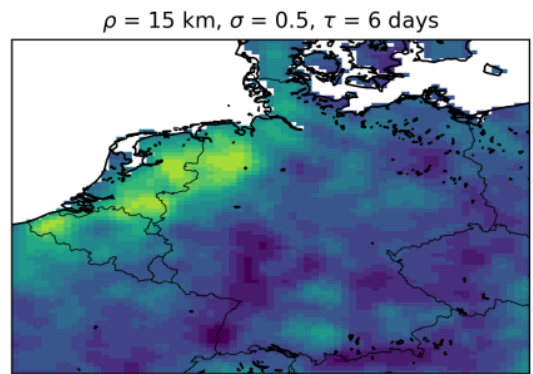

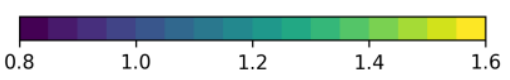

(-)

(-)

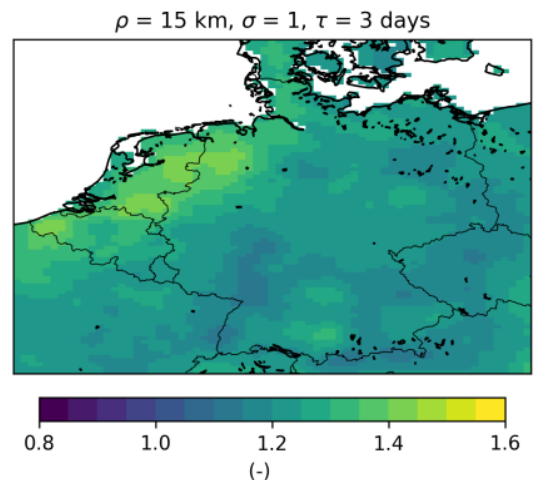

(-)

Figure S22: Mean emission perturbation factors $(\beta)$ from March to October 2014 for model runs with initially homogeneous NH3 emissions, using different local Ensemble Kalman filter settings.

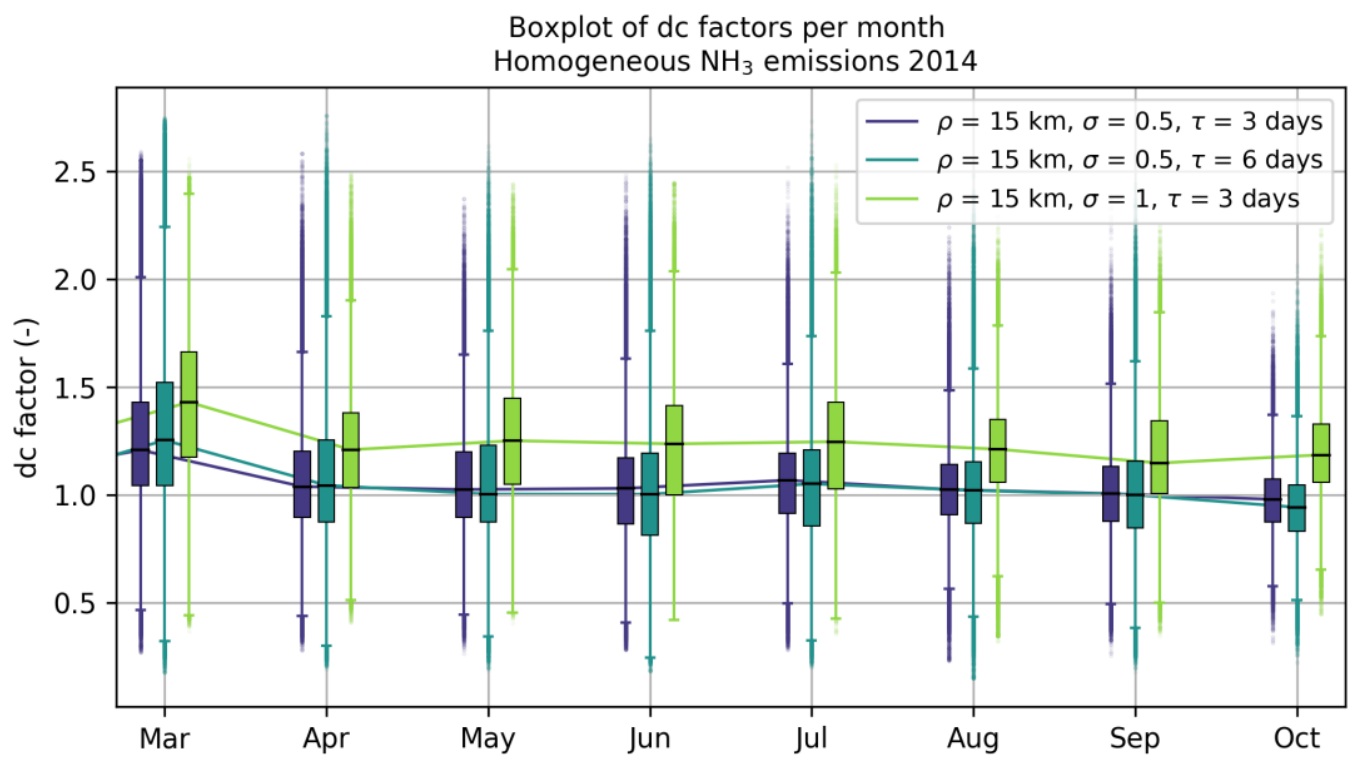

Figure S23: Distribution of emission perturbation factors $(\beta)$ per month for model runs with initially homogeneous $\mathrm{NH}_{3}$ emissions, using different local Ensemble Transform Kalman filter settings. 

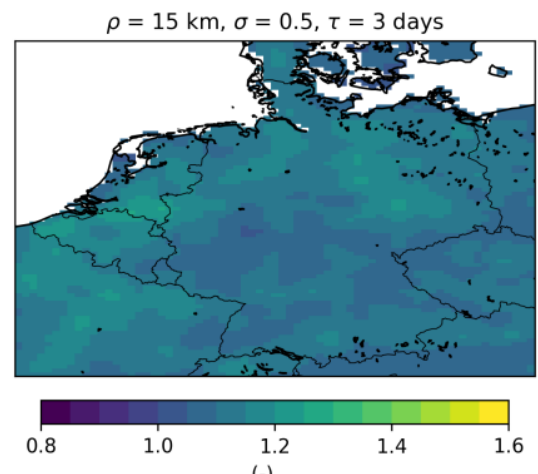

$\rho=15 \mathrm{~km}, \sigma=0.5, \tau=10$ days
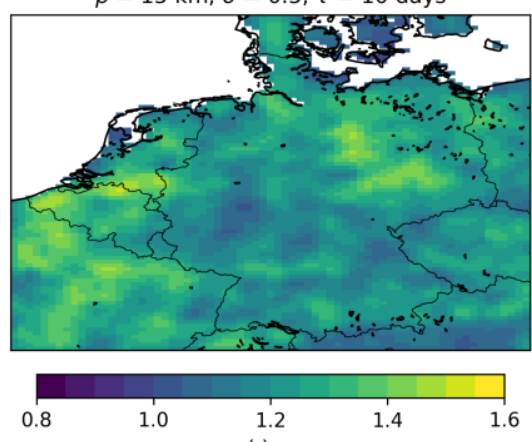

$\rho=15 \mathrm{~km}, \sigma=0.5, \tau=14$ days

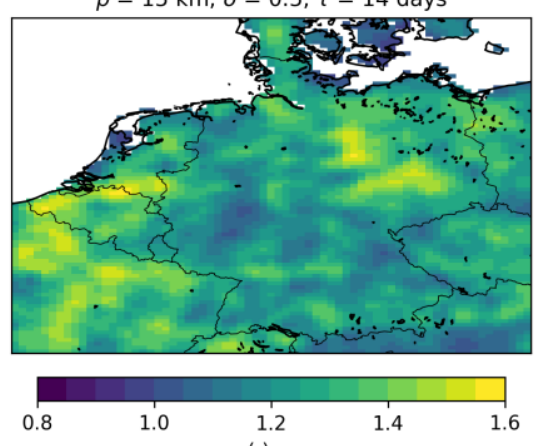

150 Figure S24: Mean emission perturbation factors $(\beta)$ in 2014 for model runs with default $\mathrm{NH}_{3}$ emissions with varying temporal correlation length $\tau$ values.

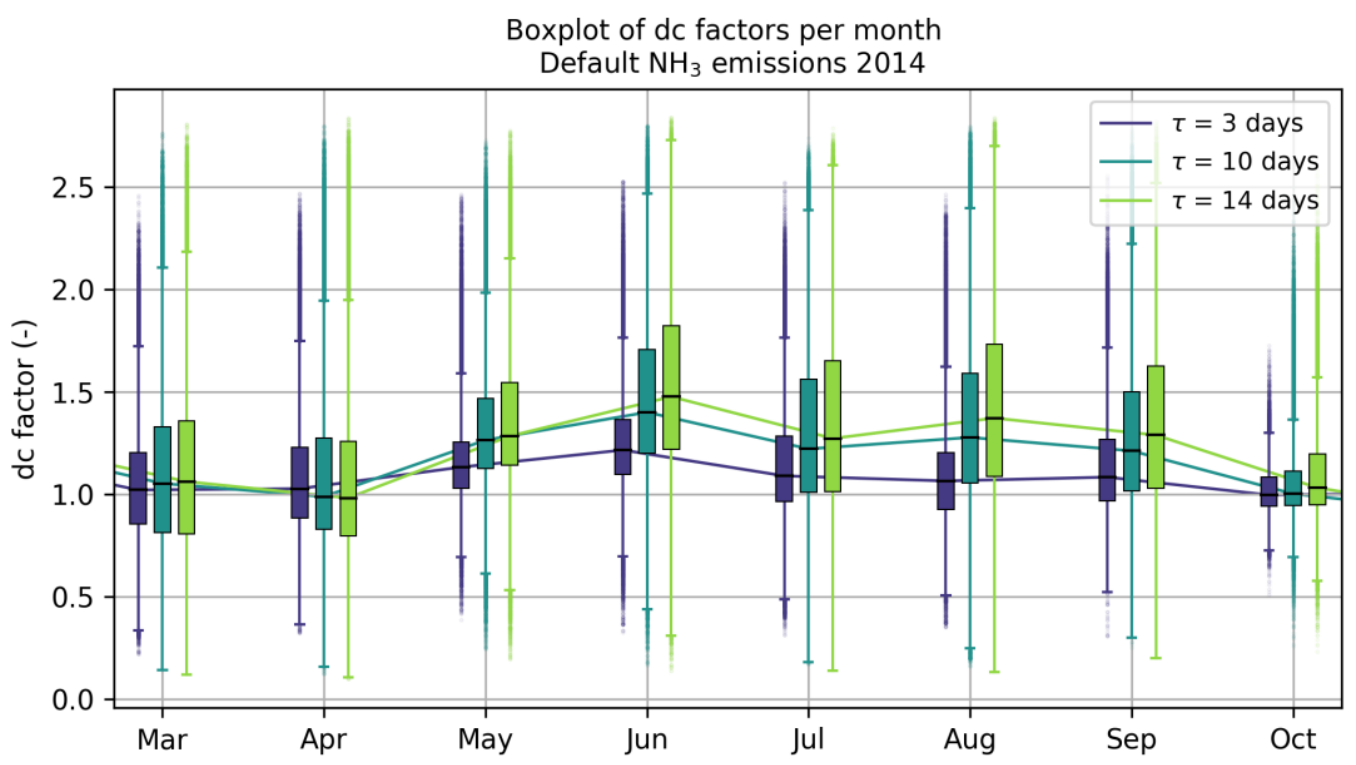

Figure S25: Distribution of emission perturbation factors ( $\beta$ ) per month for model runs with default $\mathrm{NH}_{3}$ emissions, using different values for temporal correlation length $\tau$. 